Characterising the shape of mathematics teaching decisions made over time: An application of tri-polar analysis

Nick Andrews

Department of Education, University of Oxford, Oxford, UK

Email: nicholas.andrews@education.ox.ac.uk

ORCID: 0000-0003-4388-1832 


\title{
Characterising the shape of mathematics teaching decisions made over time: An application of tri-polar analysis
}

\author{
Focussing on teachers' subject pedagogical actions over the course of a series of \\ lessons on a mathematical topic, this paper sets out an original analytical \\ approach to characterise the shape of mathematics teaching decisions made over \\ time: tri-polar analysis. The notion of manifestation is introduced as a way of \\ categorising how the teacher is observed making content available to learners and \\ the analysis explores sequencing and differences in emphasis of these categories \\ across the lesson series. These differences are presented graphically and the \\ implications for doing so in terms of opportunities for teachers' professional \\ learning are discussed. The analytical approach is exemplified through the case of \\ Ashley. Prominent between-lesson differences are discerned that suggest \\ systematic variation in what is emphasised across the lesson series, consistent \\ with deliberate and planned decision-making. But subtler between-lesson \\ differences are also revealed through the analysis associated with in-flight \\ decision-making.
}

Keywords: research methodology; classroom research; teacher education; mathematics pedagogy

\section{Introduction}

The focus of this paper is a way to characterise the decisions that teachers make regarding how they structure opportunities for learners to experience mathematical content over the course of a series of lessons on a topic. In part the motivation for the study is a classic sequencing dilemma of mathematics teaching. This is the dilemma of whether a technique is explicitly taught first before opportunities for learners to apply it are provided or instead a problem is posed so that the mathematical need for a yet-to-betaught technique arises out of working on the problem. But as well as sequencing, there is also a question of emphasis; the amount of lesson time given over to, for example, practising techniques in comparison to other aspects associated with studying a topic. 
Decisions across a series of lessons regarding sequencing and emphasis shape the way in which mathematical content is made available to learners over time. A lesson series on a particular topic is a unit of time over which teachers plan, referred to often in the UK as medium-term planning. These decisions capture the way in which a teacher intends learners to study a topic and so offer insight into that teacher's subject pedagogical thinking, most particularly around how learners learn a topic. Some decisions across the course of a lesson series may be deliberate and considered, shaped by analytical thinking. Other decisions may be intuitive or shaped by histories and culture. Considering the overall shape of teaching decisions over time when researching classroom practices captures the analytical and the intuitive, without assumptions needing to be made regarding which decisions are deliberately planned. Seeking a characterisation of the shape of these decisions is in itself a worthy aim, but it has clear impact if it draws attention to decisions around opportunities for learning mathematics that might otherwise be beyond critique by the teacher.

The impact of classroom research can be particularly powerful with respect to teacher education if it affords deep psychological investment, if findings are presented in such a way as to promote an awareness of choice, if a reason to choose to act differently can be harnessed and if alternative actions can be imagined (Mason, 2002). The goal of promoting an awareness of choice was the driving force behind developing a succinct characterisation of the shape of teaching decisions over time that might have applications for teacher education, yet a characterisation that nevertheless acknowledged the complexity of teaching. The current paper is largely concerned with presenting and justifying the approach that was developed, describing (i) the methods of analysis of teacher-talk and classroom tasks and (ii) the representation of decisions over time through a triangular chart. Elements of the design are exemplified by the case of 
Ashley working on Geometry over a series of lessons with a Year 11 class (learners aged 15-16) in a British school.

\section{Background}

The motivation for developing a characterisation of teaching decisions over time is strongly rooted in teacher education. The origins of this project are in a small pilot study conducted with three experienced teachers who were well known to me. The focus of this pilot was on the affordances of a tool to mediate reflection on mathematics teaching decisions over time. The tool was a triangular space inspired by an approach to reflection suggested by Mason (1996) and triadic models such as Jaworski's (1994) teaching triad.

For each of the teachers, I observed their lesson and afterwards met with them. I introduced the tool and was struck by how quickly they attached meaning to it. I invited them to characterise episodes from the lesson as points within the triangular space and talk about their justification for each characterisation. These were rich, and long, conversations that suggested the tool's potential to mediate reflection on mathematics teaching and to prompt the teachers to consider alternative actions. There were however two clear limitations to this approach as a way of arriving at a characterisation, as a point in the triangular space, of the overall shape of mathematics teaching decisions over time. The first was practical: given the sheer frequency of teaching decisions across a lesson (Clark \& Peterson, 1986) the total time to discuss and characterise a series of lessons on a single topic in a meaningful way by reflecting on each lesson individually was going to be prohibitive for a practising teacher, even though it offered rich opportunities for professional learning. The second was methodological: what a teacher emphasises retrospectively when talking about their teaching may not align with what they were attending to during teaching (Mason \& Davis, 2013; Speer, 2005), 
particularly if a researcher's prompts and questions shift the focus of the teacher's attention to other features.

The limitations of the approach taken in the pilot study therefore prompted the development of a research method for characterising, as a point within a triangular space, the overall shape of decisions over time and it is the results of this enterprise on which I report in the current paper.

\section{Teaching decisions}

Teachers' thinking about what to do in lessons can occur before, during and after lessons and these thoughts have been labelled as pre-active, interactive and post-active respectively (inspired by Jackson, 1968). In practice however, the post-active thoughts of one lesson and the pre-active thoughts of the next merge as reflection on one lesson informs thinking on the next. In the current paper, thinking between lessons is described as teacher planning (following Clark \& Peterson, 1986) and the term in-flight (following McNair, 1978) rather than interactive is used in order to describe decisions made during the course of a lesson. From the range of thoughts that might come to action when planning or in-flight, I am concerned in the current paper with mathematical teaching decisions. These are the decisions that relate to how mathematical content is made available to learners. Planning and in-flight decisions are often of differing grain size, but both contribute to the overall shape of mathematical teaching decisions. Planning decisions tend to shape how content is sequenced and made available to learners across a lesson or across a series of lessons. In particular, planning decisions are associated with given-task selection. I use the term given-task here to mean the task as presented on, for example, a worksheet, in a text book or spoken by the teacher as opposed to the mathematical activity initiated by such a prompt. In-flight decisions may shape how content is made available across part of a 
lesson, for example a teacher choosing to introduce an impromptu task, but more frequently shape how content is made available through teacher-talk. These two features of how content is made available (given-task and teacher-talk) are building blocks for the analytical approach that will be set out later in this paper.

Some accounts of decision-making view the mathematics teacher as problem solver, applying pedagogical and content knowledge in predictable ways in order to address concrete problems that arise in teaching. Schön (1983) uses the term technical rationality to describe such a perspective on professional practice. Individual teachers' beliefs regarding mathematics and its teaching are perceived by other authors to influence decision-making, founded on the assumption that espoused beliefs are "a significant determiner of what gets taught [and] how it gets taught" (Wilson \& Cooney, 2002, p. 128). A more situated perspective however rejects the teacher as an autonomous decision maker. Instead there is emphasis on the broader community of practice (Lave \& Wenger, 1991) or the didactical system (Chevallard, 1982), of which the teacher is part. These perspectives offer accounts for why there may be variation in how content is made available to learners in different situations: different cultures, different lessons, different classes, different topics, even different times of the year. Schoenfeld (2011) proposes a model of teacher decision-making based on psychological choice theory, seeking to explain why teachers act as they do. Key elements of the model are orientations ("dispositions, beliefs, values, tastes and preferences" (Schoenfeld, 2011, p. 29)), resources ("the information that [the teacher] has potentially available to bring to bear in order to solve problems" (Schoenfeld, 2011, p. 25)) and goals ("something that an individual wants to achieve" (Schoenfeld, 2011, p. 20) attributed to the teacher, based on observation. He segments lessons through repeated parses so as to develop a multi-layered perspective on the teacher's decision- 
making. Schoenfeld explains that the focus of his research is the teacher and, while recognising this as a potential limitation, nevertheless asserts that in classrooms where the teacher's role is an active one, a focus on the teacher "explains a significant proportion of what takes place" (Schoenfeld, 1998, p. 5). From the multi-layered perspective on a teacher's decision making that Schoenfeld offers, a teacher comes to a lesson with particular goals in mind at varying grain size: longer-term goals for multiple lessons, goals for individual lessons, and short-term goals. The teacher's resources both afford and constrain goals that are available to come to mind and the realisation of goals. Goals are reinforced while teaching, or new goals are established that take priority. These new goals are shaped by the classroom context but also by the teacher's orientations, or in Aguirre and Speer's (2000) terms, belief bundles.

Schoenfeld's interconnected model of decision-making contrasts with a more hierarchical model of strategies at varying grain size (Brown \& Coles, 2000; Brown \& Dobson, 1996). At the highest level are "teacher's images of mathematics and mathematics teaching" (Brown \& Dobson, 1996, p. 225). These images shape the midlevel strategies that Brown labels as purposes, and for each purpose there are behaviours (the lowest level strategies) associated with accomplishing the purpose. An individual teacher may, over time, develop a range of different behaviours to accomplish the same purpose, and the particular behaviour that comes to action at a given time is context-dependent. Brown and Coles (2000) offer evidence for a focus on teacher's purposes as a tool to mediate professional learning and they note how, when talking about their practice, teachers will often naturally speak at the purposes level. Further, the case is put that the foregrounding of purposes promotes teaching that is responsive to the emerging needs of learners. 
The notion of purposes is significant when considering teachers' medium-term planning. Brown and Coles (2000) note that experienced teachers are unlikely to describe their teaching in terms of specific behaviours associated with low-level strategies. Instead, "what teachers do seem to articulate are purposes" (Brown \& Coles, 2000, p.169) and a reasonable corollary to this would be that teachers' medium-term planning is similarly focussed at the mid-range level of purposes. Such purposes might include, for example, finding out what learners do and do not yet know in terms of the topic, setting up a situation in which learners might experience a particular mathematical phenomenon associated with the topic, and for learners to recognise when and how to apply a technique associated with the topic in order to solve a problem.

Planning a series of lessons can be considered as a sequencing of purposes, with this sequencing shaped at least to some extent by the teacher's high-level thinking around how students learn a topic. When enacted, these purposes can be observed as a sequence of low-level behaviours. There are parallels here with Schoenfeld's (2011) methodology for generating a multi-layered perspective on teacher decision-making. The sequencing of low-level behaviours offers one characterisation of the shape of mathematics teaching decisions over time, but one that needs to be researcherconstructed since, as has been highlighted, the teacher's attention is unlikely to be focussed on these low-level strategies over the course of a series of lessons. The sequencing of mid-level purposes offers an alternative characterisation of the shape of mathematics teaching decisions over time, but one that it is more likely that the teacher can construct for themselves given their close attention to planning at this level. Comparison of these two characterisations based upon low-level strategies and midlevel purposes respectively, particularly if different, offers a prompt for teacher reflection on mathematics teaching decisions. A further comparison is possible with 
considering alignment between both characterisations and the teacher's high-level thinking about how students learn a topic.

\section{Issues in teaching over time}

In developing a research method for characterising the overall shape of mathematics teaching decisions over time, I am firstly seeking to contribute to what is known generally about how teachers teach topics and secondly offering tools that might mediate reflection on the mathematical purposes associated with this aspect of the work of teachers and how they are accomplished. Watson (2008) highlights the lack of detailed research addressing the specific question of how teachers structure mathematical content over time. Watson's own work in this area (Watson, 2007) and the Mathematics Education Traditions of Europe project (Andrews \& Sayers, 2005) have begun to address this question, yet the current study offers an alternative approach that foregrounds opportunities for teacher learning and exploits an underlying triadic structure of topics that has parallels with the three strands of awareness, techniques and emotion that are proposed by Mason \& Johnston-Wilder (2004).

I will introduce the triadic topic structure that I am proposing with reference to specific classroom examples, in order to offer first a sense of the three elements. It should be noted however that the structure was theoretically informed rather than emerging from lesson observation, although was undoubtedly shaped by my previous experience of mathematics classrooms and somewhat refined in detail through its application to the analysis of the case reported in this paper.

When observing a teacher working with a class on geometrical constructions (as in the case of Ashley in the current paper), I might see the teacher evoking an image of a perpendicular bisector of two fixed points as the locus of points equidistant from the 
fixed points or asking learners to construct a perpendicular bisector using a straight edge and compasses. Or I might see the teacher posing the following problem:

Figure 1 shows the plan of a large rectangular hall with three exits marked A, B and C. At the end of an event in the hall, people are asked to leave by the exit that is nearest to them. Shade on the plan the part of the hall for which people would need to leave by exit A.

A

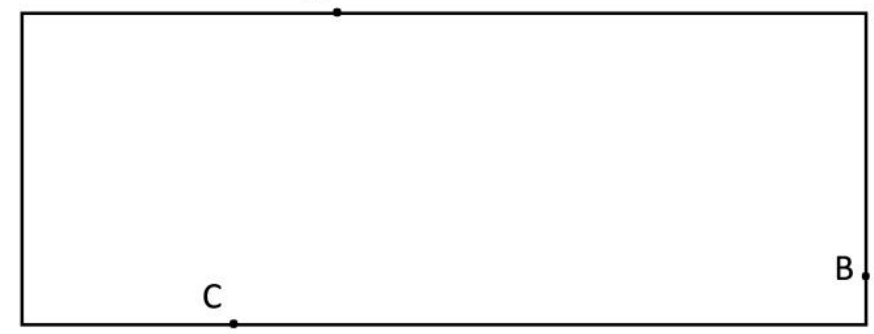

Figure 1: Plan of the hall for the exit problem.

I describe each example as a manifestation of a perpendicular bisector. In developing a research method to characterise the overall shape of mathematics teaching decisions made over time, I am not seeking what the teacher perceives as the form of content they are offering, for which I might use the term representation. Rather it is the perception of what is being offered from the position of observer, for which I use the term manifestation. Manifestation refers to the observation of how content is made available to learners by the teacher through the combination of given-tasks and teachertalk as defined previously. Furthermore, I take manifestation to be the way in which a teacher's mathematical decision-making is manifested in the classroom and hence, in the current study, it is the sequencing of manifestations that is used in order to characterise the shape of mathematics teaching decisions over time.

Each example above is a different manifestation of a perpendicular bisector. I classify the imagery of the locus of points as visual, the construction procedure as 
technical and the exit problem as functional (in the sense that a solution is likely to be arrived at through modelling the problem mathematically). The three components of manifestation may be combined, for example if the teacher was observed offering the exit problem above as a given-task and heard saying "Solve this by constructing the perpendicular bisector of each pair of points A, B and C"; this would be both a functional and a technical manifestation of a perpendicular bisector. In other cases, the spoken instruction may not be so explicit but nevertheless clearly implied in the context of the lesson. Either way, I would classify what I observe being offered as functionaltechnical. Similarly, manifestations might be classified as visual-functional or visualtechnical, or indeed visual-functional-technical. The relationship between mathematical teaching decisions, given-tasks, teacher-talk, manifestation and the characterisation, as a point within a triangular space, of the shape of mathematics teaching decisions over time is summarised succinctly in Figure 2.
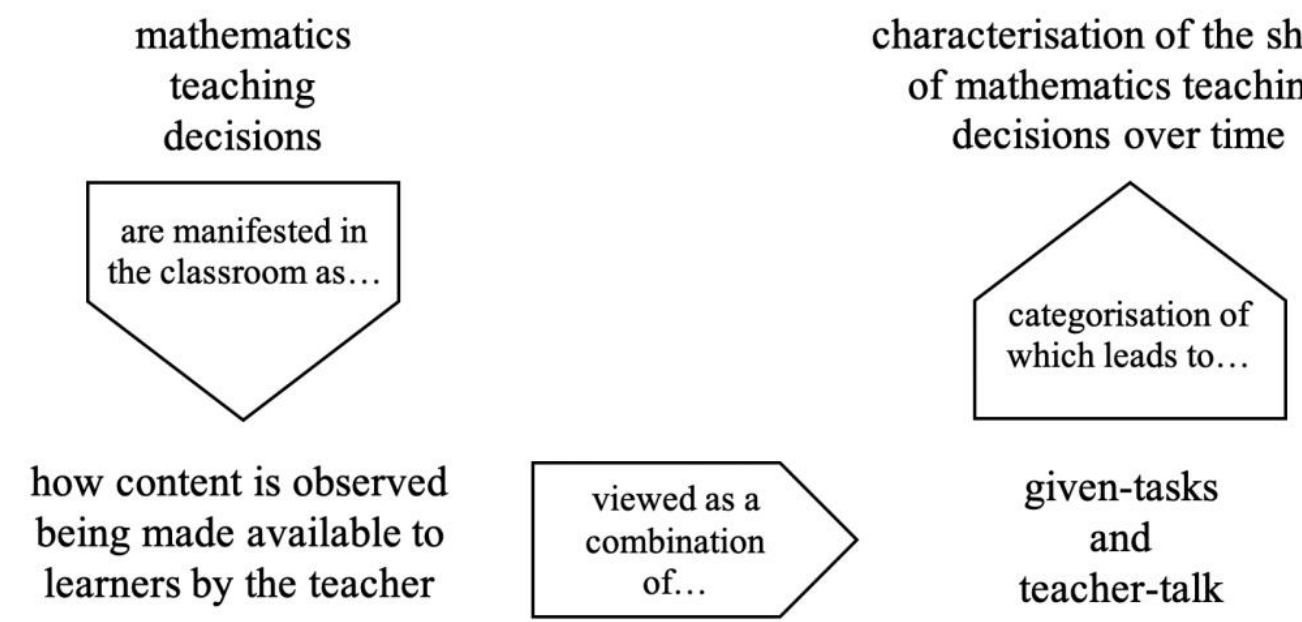

given-tasks

and

teacher-talk

Figure 2: The relationships between the key constructs in the current study:

mathematics teaching decisions, how content is made available to learners, given-tasks and teacher-talk, and the characterisation of the shape of mathematics teaching decisions over time. 
Although the classification of manifestations has been established above through focussing on geometrical constructions, it is transferable to other topics not under consideration in this paper. For example, when teaching linear equations, I might see the teacher offering diagrams of bars as in Figure 3 (visual), mathematical symbols such as " $5 x+3=24-2 x$ " (technical), or word problems (functional) such as "My father is currently three times my age. In five years' time the sum of our ages will be 50 . How old am I now?"

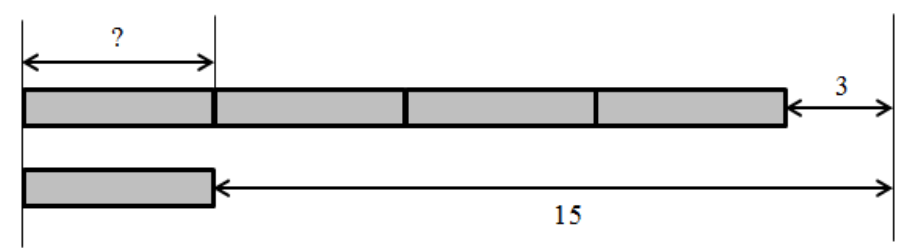

Figure 3: A bar problem; a visual manifestation of linear equations.

The distinctions between visual, functional and technical manifestations can also be seen in the study conducted by Vappula and Clausen-May (2006) who contrasted student performance in diagram context (visual), story context (functional) and abstract (technical) items. The broad scope of functional manifestation is captured well by Drake, Wake and Noyes's (2012) typology of functional mathematics. Two senses of the notion of functional manifestation can also be seen in the works of Hoogland, Pepin, de Koning, Bakker and Gravemeijer (2018): wordiness and pictorial complexity. While the diagrammatic representation of problematic situations in their study involves pictures, these are pictures of objects in the material world and so would not be categorised as visual in the sense it is being used in the current framework Considering possible implications for learning adds further texture to these descriptions, and to do this I draw on Pirie and Kieren's (1989) model of growth in understanding. This model consists of eight concentric layers, going from the central 
primitive knowing through image making, image having, property noticing, formalising, observing, and structuring to the outermost layer inventising. Shaped by a constructivist perspective, it represents the dynamic process of learners coming to understand (Pirie \& Kieren, 1994). Understanding of one concept at the outer layer can be the primitive knowing of another concept. A further feature of the model is what the authors describe as don't need boundaries, between image making and image having, between property noticing and formalising, and between observing and structuring. They note: 'beyond these boundaries the learner is able to work with notions that are no longer tied to previous forms of understanding' (Pirie \& Kieren, 1994, p.173).

Image having, formalising and structuring are therefore particularly significant to growth in understanding as they each lie beyond a don't need boundary. Image having involves the learner working visually with mental images without needing to act on material objects. Formalising might also be referred to as method having or definition having, so follows abstraction of a formal method or definition typically from the previously held image. Structuring involves accommodating into a wider mathematical context the method or definition that is the result of formalising and has parallels with Kilpatrick, Swafford and Findell's (2001) notion of adaptive reasoning. I associate opportunities to focus learners' attention on image having, formalising and structuring (Pirie \& Kieren, 1989) with observing the teacher offer visual, technical and functional manifestations respectively.

On the other hand, I associate observing the teacher offer visual-functional, visual-technical and functional-technical manifestations with opportunities to shift the focus of learners' attention; these are likely to afford learners new ways in which to encounter a mathematical phenomenon working from what is already familiar. Teachers' problem posing in the classroom is largely associated with functional 
manifestation, however the interplay with the visual and technical elements offers a useful distinction. Problems that call for the application of a particular method are visual-technical manifestations, for example, Foster's notion of mathematical étude concurrently affords both opportunity for "development of fluency on a specific skill" and "independent problem solving" (Foster, 2013, p. 768). In contrast, root problems featured frequently in the lesson series on geometrical constructions on which I focus below. These are problems whose solutions are associated with image making (Pirie \& Kieren, 1989): drawing on learners' primitive knowledge of a topic in order to evoke a sense of a new mathematical phenomenon. A root problem is typically classified as a visual-functional manifestation, since it features both functional and visual components. For example, Brown and Coles (2000) report on a lesson episode that drew on what learners already knew about linear relationships between two variables (including expressing these relationships algebraically) in order to offer an image of simultaneous linear equations as two conditions with the property that the second condition narrows to just one pair the set of ordered pairs that fulfil the first condition.

As a reflective tool, the visual-functional-technical triad offers a vocabulary for articulating how mathematical content is made available over time and allows for comparison between topics. It offers a way of drawing distinctions between the mathematical purposes (in the sense of Brown \& Dobson, 1996) of different episodes (e.g. different lessons) within a lesson series, such as different lessons. Furthermore, distinctions between the mathematical purposes of different lesson events (Clarke, Emanuelsson, Jablonka, \& Mok, 2006) can also be expressed, such as classwork and seatwork. Here classwork means the teacher "working with all the students and, usually, orchestrating the discussion" (Stigler and Hiebert, 1999, p. 67) and classroom talk being public. Seatwork is "when students work individually or in small groups on assigned 
tasks" and "talk is mostly private — teacher-student or student-student" (Stigler \& Hiebert, 1999, p. 67).

I will now turn specifically to how the triad, combined with an approach I refer to as tri-polar analysis, offers a research method for characterising how content is made available over time.

\section{Methodology}

I refer to the research method developed for characterising the overall shape of decisions over time regarding how content is made available to learners as tri-polar analysis of manifestation. Reflecting on this design, it was evident that there was a generalisable approach that could be applied to explore phenomena other than manifestation. I refer to this general approach as tri-polar analysis. While the main focus here is on the specific application to manifestation, I will highlight general features through the structure of this methodology section. There are two stages to tripolar analysis that I refer to as the quantitising and descriptive analysis stages. Both of these stages will be explained and then exemplified in the context of the current study in the following sub-sections.

A fundamental perspective that shapes the design of tri-polar analysis is that data is not present in the social world ready for collection and analysis but rather is a product of a researcher's move to present experience as data. From this perspective, qualitative and quantitative data are "experiences formed into, for example, words or numbers, respectively" (Sandelowski, Voils, \& Knafl, 2009, p. 209). To this I would add the possibility of experience formed into images and represented graphically. It is this graphical characterisation of experience that is a further distinctive feature of tripolar analysis. A final feature of the approach to emphasise at this stage is that it allows for analysis at different grain sizes. These are nested units of analysis, such as the lesson 
and lesson series that are explored here, but these build on a fine-grain analysis at a smaller unit to be determined in the context of the research. Following piloting, for this study an interval of $30 \mathrm{~s}$ of lesson time was chosen as the smallest unit of analysis for how the teacher was observed to make content available. This unit size is large enough so as to be able to represent the complex nature of the how content is made available but small enough for reliable coding of the presence of particular manifestations.

\section{Quantitising stage}

Central to tri-polar analysis is a way of characterising experience graphically, but in order to do so it is first necessary to characterise experience quantitatively. In the current study data as collected is qualitative. Conversion of qualitative data into quantitative data is labelled as quantitising within the Mixed Methods literature (Sandelowski et al., 2009; Seltzer-Kelly, Westwood, \& Pena-Guzman, 2012; Teddlie \& Tashakkori, 2003). Quantitisation affords drawing inferences that are not available to be drawn through observation alone, often because the object of inquiry is people's intentions or is hidden within the complexity of a situation. It is particularly the latter that offers a rationale for such a conversion of data featuring in the current study. Below I set out how manifestations that the teacher was seen offering over each 30 -second interval were characterised quantitatively.

What the teacher was observed making available to learners over a series of lessons is treated as a text for analysis. This text includes everything the teacher was heard to say (which was converted into written text by audio recording the teacher's voice and producing a transcript from this recording), all images he or she was seen to offer and all printed resources he or she provided over the series of lessons that pertain to the topic at hand. It represents the union of opportunities to learn, because it is recognised that not all teacher-talk was available to all learners (for example, it might be 
spoken privately to individual learners) and that not all given-tasks may be available to all learners (for example, this might be within the teacher's plan, or the given-task is not accessible to the learner or the learner chooses not to engage with the given-task). The text is parsed into 30-second intervals, each of which is then qualitatively coded for manifestation using the categories in the first column of Table 1. Multiple manifestation categories may be present in a given interval, for example there may have been a change in given-task during the interval or the given-task may be coded differently to teacher-talk.

Barycentric co-ordinates provide a way of representing quantitatively the relative stressing of the three components of the triad \{visual, functional, technical\}. The co-ordinate $(v, f, t)$ represents a relative stressing of the three components in the ratio $v: f: t$, with the condition that $v+f+t=1$. The second column of Table 1 indicates the Barycentric co-ordinate associated with each of the manifestation categories that may be present in a given interval. The quantitative code for the interval (also referred to as the interval centre) is the mean of the Barycentric co-ordinates of all of the manifestation categories present in that interval. For example, an interval featuring a given-task categorised as visual-functional and teacher-talk categorised as technical would have interval centre $([1 / 2+0] \div 2,[1 / 2+0] \div 2,[0+1] \div 2)=(1 / 4,1 / 4,1 / 2)$. 


$\begin{array}{cc}\text { Visual } & (1,0,0) \\ \text { Visual-functional } & (1 / 2,1 / 2,0) \\ \text { Functional } & (0,1,0) \\ \text { Functional-technical } & (0,1 / 2,1 / 2) \\ \text { Technical } & (0,0,1) \\ \text { Visual-technical } & (1 / 2,0,1 / 2) \\ \text { Visual-functional-technical } & (1 / 3,1 / 3,1 / 3)\end{array}$

Table 1: Manifestation categories that could be present in a 30-second interval and their associated Barycentric co-ordinates.

In order to exemplify the quantitising stage, Figure 4 is an instance of a giventask from my data. This problem was posed along with an explicit instruction from the teacher that one of the standard geometrical constructions the class had worked on previously could be applied in order to solve it. In other classroom contexts, this giventask might be categorised as functional. But given the explicit instruction from the teacher drawing attention to a possible method of solution, the given-task is categorised as functional-technical here.

There are two toilets A and B marked on a map of a festival site. Tom wants to walk between the two toilets so that he stays as far away from each of them as he can! Draw the path Tom walks along.

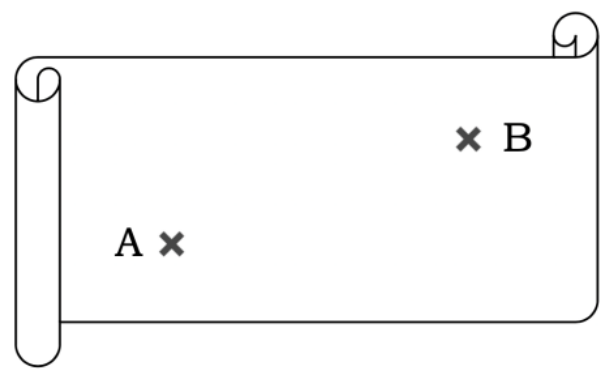

Figure 4: A given-task categorised as functional-technical. 
While the class was working on this problem, the teacher was recorded within one 30-second interval saying to a learner about an example that had been drawn previously in the learner's notebook of the perpendicular bisector of two points. The teacher continued by saying, "We had the two points. You drew a circle around there and a circle around there and that shows where the line goes between the two points." This teacher-talk is emphasising a method of construction, and is categorised as technical. This 30 -second interval therefore features a given-task categorised as functional-technical and teacher-talk categorised as technical, so would have interval centre $([0+0] \div 2,[1 / 2+0] \div 2,[1 / 2+1] \div 2)=(0,1 / 4,3 / 4)$.

\section{Descriptive analysis stage}

The second stage of tri-polar analysis is described as descriptive because it offers both a quantitative and graphical characterisation of lessons (or lesson series) and so indicates possible differences between them. Following Mason (1996) and Swan (2007), a triangular space may be used to characterise graphically a categorisation of any experience of a phenomenon conceptualised as having an underlying triadic structure. The vertices of the triangle can be thought of as attracting poles representing the three components: the more the component is stressed, the greater attraction there is to the pole representing that component, so the closer the point is to that pole. This imagery gives rise to the term tri-polar space that I use to label this graphical characterisation of experience. The tri-polar space for manifestation is given in Figure 5. The three poles are labelled visual, functional and technical. $\mathrm{M}$ is the centroid of the triangle representing a perfect balance of the three components. Movement away from $\mathrm{M}$ in the direction of arrows (a), (b) and (c) represents an increased stressing of the visual, functional and technical components of manifestation respectively. 


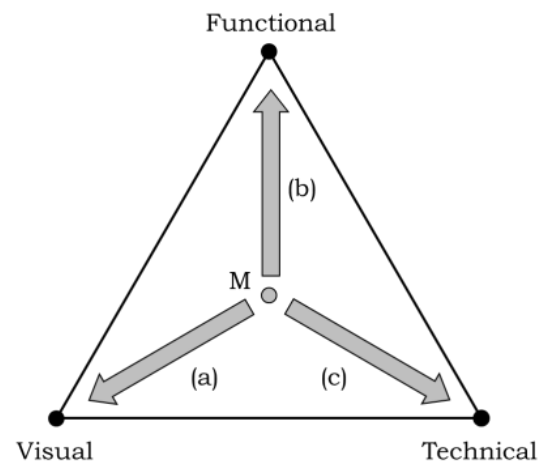

Figure 5: Tri-polar space for manifestation.

Each point within the interior of a tri-polar space corresponds to a Barycentric co-ordinate $(v, f, t)$ with $v+f+t=1$, and so each interval centre may be represented graphically through a point within the space. The mean of interval centres over a longer time period determines the central point for that period. This process is used in order to determine lesson and lesson series centres for manifestation. Each such centre graphically characterises the relative stressing of visual, technical and functional components of manifestation over that unit of time and the Barycentric co-ordinates of this point provide a quantitative characterisation. The graphical characterisation allows for a visual comparison of lessons within a series and also between lesson series in order to reveal differences in the shape of mathematics teaching decisions, whereas the quantitative characterisation allows for these comparisons to be done numerically.

As a technical aside, it might be noted that there are only a finite number of points within the tri-polar space where an interval centre can be positioned and therefore there are only a finite number of points where a lesson series centre can be positioned by the analysis. This represents a finite sub-set of the infinite sets of points where a teacher being invited to mark a point intuitively within the space can position a lesson series centre. 


\section{Exemplification of the application of tri-polar analysis}

In order to exemplify how tri-polar analysis can be applied to a series of lessons, I will focus on the case of Ashley, a teacher of a Year 11 class (learners aged 15 to 16) in a British school. Ashley was working with the class on geometrical constructions over a series of five one-hour lessons. Through conducting a tri-polar analysis of the teachertalk and given-tasks offered over the course of this lesson series and focussing on the manifestations that the teacher was observed offering I sought to characterise the shape of mathematical teaching decisions made during: (i) the lesson series overall; (ii) each lesson within the series; (iii) seatwork when compared to classwork.

This section has been divided into two parts with the intention of providing evidence for the validity of the findings that follow from tri-polar analysis. In the first part, I offer a narrative account of the lesson series so that the reader can form an image of Ashley's teaching over the lesson series. Then I set out my analysis of the lesson series. Finally, I draw attention to features of the narrative account that are foregrounded by the analysis but also highlight findings from the analysis that are less immediately discernable from the narrative account or not discernable at all.

\section{Narrative account of Ashley's lesson series}

In this narrative account of the lesson series, I focus on the content of each segment of each lesson in the series. By segment here I mean a part of a lesson that addresses a particular mathematical purpose. Typically, given that my focus is on the teacher, I do this by describing the task prompts (the given-task) and explanations (teacher-talk) that Ashley offered the class.

In Lesson 1, Ashley provided opportunities for learners to experience each of the circle (Segment 1), the perpendicular bisector (Segment 2) and the angle bisector 
(Segment 3) as a locus of points constrained by a particular rule. Each lesson segment followed a similar pattern with Ashley posing a root problem and then offering a formal method of construction. For example, in the first segment, learners were initially instructed to plot points a fixed distance from a given point, allowing them to notice that this results in a circle:

On a piece of blank paper put $[\ldots]$ a small cross, in the middle [...] I would now like you to mark a dot $5 \mathrm{~cm}$ away from your cross [...] I would like you to draw another dot $5 \mathrm{~cm}$ away from the cross. Then I'd like you to draw a third dot $5 \mathrm{~cm}$ away from the cross. In fact I'd like you to draw ten thousand dots $5 \mathrm{~cm}$ away from the cross.

(Ashley, Year 11 Geometry Lesson 1)

Having worked on this root problem, those learners who had not done so already by their own volition were directed to use a pair of compasses in order to construct the circle of radius $5 \mathrm{~cm}$ centred on the cross they had originally marked. Following the root problem in the next lesson segment, Ashley demonstrated the construction of a perpendicular bisector to the whole class. A video of the construction of an angle bisector was shown following the root problem in the final lesson segment of this first lesson.

In the second lesson of the series, learners generated further examples of the ruler and compass constructions met so far. Ashley set learners the task of constructing:

(1) A circle of radius $6 \mathrm{~cm}$.

(2) The perpendicular bisector of two points of their choice.

(3) The angle bisector of: (a) an acute angle, (b) an obtuse angle, (c) a reflex angle, (d) a $180^{\circ}$ angle (as a way of constructing a perpendicular from a point on a line)

(4) An angle of $22.5^{\circ}$. 
At the start of Lesson 3, Ashley posed a problem that required learners to apply a construction the class had worked on towards the end of Lesson 2. Following this, two further constructions were introduced: the perpendicular to a line passing through a given point and the triangle (given the lengths of its three sides). As in Lesson 1, this was through Ashley posing root problems and then discussing the formal method with the whole class.

Learners were provided with two worksheets during Lesson 4 featuring opportunities to apply geometrical constructions in order to solve problems. The following is an example from the second worksheet:

\footnotetext{
$\mathrm{ABCD}$ is a rectangular field [ $\mathrm{AB}$ is 85 metres, $\mathrm{AD}$ is 45 metres]. Treasure is hidden in the field! The treasure is at an equal distance from the sides $\mathrm{AB}$ and $\mathrm{AD} \ldots$ [and] is also 60 metres from the corner C [...] Mark the position of the treasure with an $\mathrm{x}$.

(Worksheet, Year 11 Geometry Lesson 4)
}

Learners continued to work on the second of these worksheets in Lesson 5.

\section{Tri-polar analysis of Ashley's lesson series}

Narrative accounts can offer rich descriptions of the experiences of lessons, but they are not necessarily intended to capture a temporal dimension, nor can they always hope to capture the overall shape of teaching decisions made over time, both those that result from analytical thinking and those that are intuitive (and potentially pass unnoticed). In this section I show how these limitations may be overcome through tri-polar analysis, as this was purposefully developed in order to capture the timing and nature both of the given-task and what Ashley offered learners through teacher-talk following on from the initial task prompt. Similarities in the nature of what Ashley offers that are apparent in the narrative account are detected by the analysis, but so too are the subtle differences 
that arise from differences in the nature of teacher-talk and these are signified by noncoincident lesson centres within the tri-polar space for manifestation.

The coarsest level of analysis characterises graphically through the tri-polar space for manifestation the relative stressing across the lesson series of the visual, functional and technical components. The series centre for manifestation for Ashley's lesson series on geometry (Figure 6) indicates a stressing of the technical component $(t$ $=0.50)$ over the visual $(v=0.26)$ and functional $(f=0.24)$ components. Given the emphasis on construction, this stressing of the technical component revealed by the quantitative analysis would be expected.

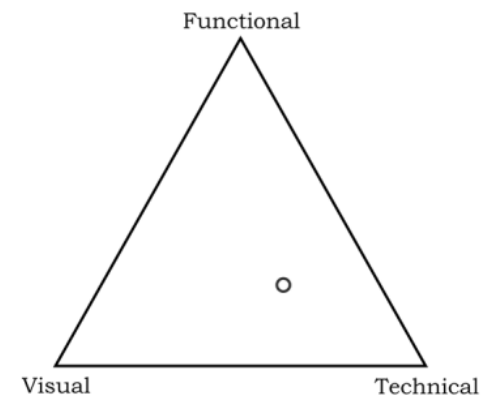

Figure 6: Series centre for manifestation for Ashley's lesson series on geometry.

A finer level of analysis characterises graphically through the tri-polar space for manifestation the relative stressing of the visual, functional and technical components within each lesson. For Ashley's lesson series, analysis at the lesson level reveals differences in emphasis from lesson to lesson (see Figure 7). Furthermore, there was a decrease across the lesson series in the stressing of the visual component. 


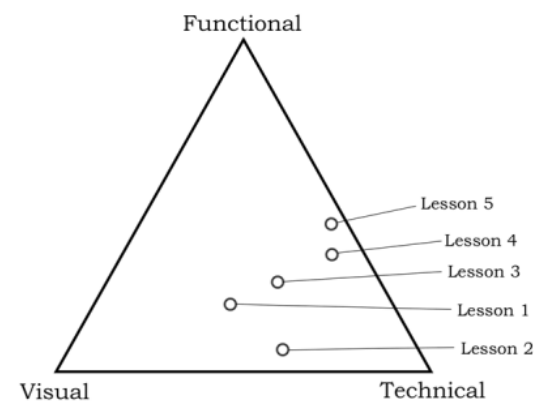

Figure 7: Lesson centres for manifestation for Ashley's lesson series on geometry.

It is possible to match some of these between-lesson differences with reference to the narrative lesson accounts given above, and this contributes to assessing the validity of the graphical characterisations. Lesson 1 and 3 were largely concerned with offering learners root problems from which formal methods followed (visual, functional and technical components of manifestation foregrounded), although Lesson 3 also included learners applying a construction in order to solve a problem (functional and technical components particularly stressed). Lesson 2 mainly featured opportunities for learners to generate their own examples of constructions (visual and particularly technical components of manifestation foregrounded). In Lessons 4 and 5 they used these constructions in order to solve problems (functional and technical components foregrounded).

There were three very distinctive ways in which Ashley made content available to learners that were observable across the lesson series, with similarities in mathematical purpose between Lessons 1 and 3 (to offer learners a sense of, and then a technique for, constructing particular geometrical phenomena), and between Lessons 4 and 5 (for learners to recognise when and how to use geometrical constructions in order to solve problems), but this finer-grain analysis reveals both of these pairs of lessons different to each other and to Lesson 2. Such differences in what at a surface level seem similar-in-purpose lessons from their narrative accounts arise from differences in the 
nature of teacher-talk following on from the initial task prompts that occur in these lessons and also differences in time given over to the different-in-purpose segments that constitute the lessons.

Tri-polar analysis can offer a characterisation of the shape of mathematics teaching decisions within different lesson events. It is unlikely that this contrast could be made based on observation or reflection on action alone. By categorising each 30second interval as either classwork or seatwork based on Stigler and Hiebert's (1999) definitions, a series centre for each category can be calculated. Of the 487 30-second intervals in Ashley's lesson series, 77 were categorised as classwork (16\%) and 410 seatwork (84\%). The tri-polar space for manifestation in figure 8 indicates differences in what was made available during each lesson event, with a greater stressing of the visual element during classwork and functional element during seatwork when the two lesson events are compared.

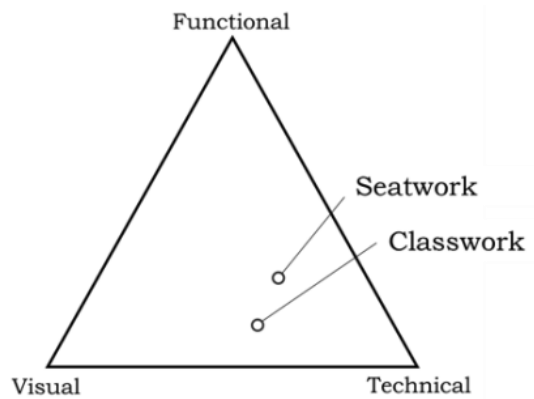

Figure 8: Series centres for manifestation for Ashley's lesson series on geometry for the separate lesson events of classwork and seatwork.

\section{Discussion of tri-polar analysis of manifestation and its potential}

In this paper I have set out an original analytical approach to characterise the shape of mathematical teaching decisions made over time. Some of these decisions will be deliberate and considered whereas other may be intuitive. Focussing on differences in how content was observed to be made available between lessons, I am able to 
characterise changes in mathematical purpose over time. The reasons behind these decisions are not intended to be addressed by this analysis. The graphical characterisation of the shape of mathematical teaching decisions over time however does offer a prompt for exploring decisions with teachers and I will expand on this point below.

In presenting the case of Ashley, I have exemplified applications of tri-polar analysis. The first application focussed on between-lesson differences in how content was made available when teaching a topic. The additional insights into differences that this approach offers over narrative accounts of lessons arising from observation may appear modest. Lessons 1 and 3 were noticeably different from observation alone to Lessons 4 and 5 for example. Both analyses suggest systematic variation in what is emphasised across the lesson series, consistent with deliberate and planned decisionmaking. The tri-polar analysis however discerns subtle differences between Lesson 1 and Lesson 3 and between Lesson 4 and Lesson 5, likely to be associated with in-flight decision-making, that the narrative account does not. It therefore captures a more complex progression through the topic than the movement from visual through technical towards functional that the narrative accounts suggested, picking up on how teacher-talk enriches the progression through given-tasks. The second application, focussing on differences between lesson events, points to how the analysis can draw attention to features of how content is made available over time that may not be possible to capture through observation or reflection on action. Finding that what is emphasised mathematically varies by lesson event creates the possibility of the relationship between mathematical purpose and mode of classroom interaction becoming a focus for professional learning through on-going analysis. 
Tri-polar analysis can be, and has been, applied to address other research questions. The case of Ashley was part of a larger project that studied a further three cases of teachers teaching a series of lessons. As well as exploring between-lesson and between-lesson-event differences for each case, the approach allows for comparison between cases. It is possible to explore for instance whether the topic rather than the teacher is the more significant factor in how content is made available over time (Andrews, 2017).

A current limitation of tri-polar analysis being applied to support teacher reflection is the time taken to run the analysis itself. To this point the intention has only been to demonstrate the potential of the concept of the analysis and a systematic study has yet to be conducted to explore the criticality of elements of the design such as the choice of $30 \mathrm{~s}$ of lesson time as being the smallest unit of analysis rather than a longer time period and the need for transcription of teacher-talk in order to enable categorisation of each interval. Further consideration also needs to be given to its role in supporting reflection. Focussing on the absolute positions of lesson and lesson series centres within the tri-polar space generated by the analysis may not be as productive as comparing the relative positions of two or more centres. So, asking a teacher following a lesson "Where would you place the lesson centre for this lesson?" and comparing this to the centre generated by the analysis might not allow for reflection as much as asking "Where would you place the lesson centre relative to the previous lesson?" and comparing this to the relative positions of the two centres generated by the analysis. A general point arising from this is that no normative judgements have been made yet using the tri-polar space such as where a lesson or series centre might generally be expected to be positioned or typically what path a sequence of lesson centres might trace through the space. Currently the reasons against doing so are matters of principle: 
that the space is offered as a way of opening up what might be possible rather than narrowing to what might be typical.

But I conclude that, following Mason (2002), if findings can be presented in order to promote an awareness of choice, if a reason to choose to act differently can be harnessed and if alternative actions can be imagined then there is a good potential for classroom research to have an impact on teachers' pedagogical actions. This conviction is what motivated the graphical characterisation of the shape of mathematical teaching decisions made over time through the tri-polar space for manifestation and the design of the analysis that facilitates this. Lesson and lesson series centres plotted within the tripolar space characterise the shape of mathematical teaching decisions, and these prompt reflection particularly if compared to intentions, what is personally espoused or what the teacher senses as external expectations. The interior triangular space suggests the possibility of choice and invites actions associated with particular positions within it to be imagined. This activity in turn invites new research opportunities to explore teachers' classroom practices.

\section{Declaration}

No potential conflict of interest was reported by the author.

\section{References}

Aguirre, J., \& Speer, N. (2000). Examining the relationship between beliefs and goals in teacher practice. Journal of Mathematical Behaviour, 18(3), 327-356.

Andrews, N. (2017, February). Differences in the forms of content teachers are seen to offer over time: Identifying opportunities for teacher growth. In T. Dooley \& G. Gueudet (Eds.). Proceedings of the tenth congress of the European society for research in mathematics education (pp.3232-3239). Dublin, Ireland: DCU Institute of Education \& ERME. 
Andrews, P., \& Sayers, J. (2005). How do teachers of mathematics teach? A four-way international comparison. Research in Mathematics Education, 7(1), 139-158.

Brown, L., \& Coles, A. (2000). Complex decision making in the classroom: The teacher as an intuitive practitioner. In T. Atkinson \& G. Claxton (Eds.), The intuitive practitioner: On the value of not always knowing what one is doing (pp. 165181). Buckingham, UK: Open University Press.

Brown, L., \& Dobson, A. (1996). Using dissonance - finding the grit in the oyster. In G. Claxton, T. Atkinson, M. Osborn, \& M. Wallace (Eds.), Liberating the learner: Lessons for professional development in education (pp. 212-227). London, UK: Routledge.

Chevallard, Y. (1982). Pourquoi la transposition didactique? [Why didactical transposition?] Retrieved from http://yves.chevallard.free.fr/spip/spip/article.php3?id_article=103.

Clark, C., \& Peterson, P. (1986). Teachers' thought processes. In M. C. Wittrock (Ed.), Handbook of research on teaching (third edition) (pp. 255-296). New York, NY: Macmillan.

Clarke, D., Emanuelsson, J., Jablonka, E., \& Mok, I. (eds.). (2006). Making connections: Comparing mathematics classrooms around the world. Rotterdam, Netherlands: Sense Publishers.

Drake, P., Wake, G., \& Noyes, A. (2012). Assessing 'functionality' in school mathematics examinations: What does being human have to do with it? Research in Mathematics Education, 14(3), 237-252.

Foster, C. (2013). Mathematical etudes: Embedding opportunities for developing procedural fluency within rich mathematical contexts. International Journal of Mathematics Education in Science and Technology, 44(5), 765-774.

Hoogland, K., Pepin, B., de Koning, J., Bakker, A., \& Gravemeijer, K. (2018). Word problems versus image-rich problems: An analysis of effects of task characteristics on students' performance on contextual mathematics problems. Research in Mathematics Education, 20(1), 37-52.

Jackson, P. (1968). Life in classrooms. Reissued as Jackson, P. (1990) Life in classrooms. New York, NY: Teachers College Press.

Jaworski, B. (1994). Investigating mathematics teaching: A constructivist enquiry. London, UK: The Falmer Press. 
Kilpatrick, J., Swafford, J., \& Findell, B. (2001). Adding it up: Helping children learn mathematics. Washington, DC: National Academy Press.

Lave, J., \& Wenger, E. (1991). Situated learning: Legitimate peripheral participation. Cambridge, UK: Cambridge University Press.

Mason, J. (1996). Personal enquiry: Moving from concern towards research. Milton Keynes, UK: The Open University.

Mason, J. (2002). Researching your own practice: The discipline of noticing. Abingdon, UK: Routledge.

Mason, J., \& Davis, B. (2013). The importance of teachers' mathematical awareness for in-the-moment pedagogy Canadian Journal of Science, Mathematics and Technology Education, 13(2), 182-197.

Mason, J., \& Johnston-Wilder, S. (2004). Fundamental constructs in mathematics education. Abingdon, UK: RoutledgeFalmer.

McNair, K. (1978). Capturing in-flight decisions: Thoughts while teaching. Educational Research Quarterly, 3(4), 26-42.

Pirie, S., \& Kieren, T. (1989). A recursive theory of mathematical understanding. For the Learning of Mathematics, 9(3), 7-11.

Pirie, S., \& Kieren, T. (1994). Growth in mathematical understanding: How can we characterise it and how can we represent it? Educational Studies in Mathematics, 26(2), 165-190.

Sandelowski, M., Voils, C. I., \& Knafl, G. (2009). On quantitising. Journal of Mixed Methods Research, 3(3), 208-222.

Schoenfeld, A. H. (1998). Toward a theory of teaching-in-context. Issues in Education, 4(1), 1-94.

Schoenfeld, A. H. (2011). How we think: A theory of goal-oriented decision making and its educational applications. Abingdon, UK: Routledge.

Schön, D. A. (1983). The reflective practitioner: How professionals think in action. Reprinted as D. A. Schön (2011) The Reflective Practitioner: How professionals think in action. Farnham, UK: Ashgate.

Seltzer-Kelly, D., Westwood, J., \& Pena-Guzman, M. (2012). A methodological selfstudy of quantitizing: Negotiating meaning and revealing multiplicity. Journal of Mixed Methods Research, 6(4), 258-274. 
Speer, N. M. (2005). Issues of methods and theory in the study of mathematics teachers' professed and attributed beliefs. Educational Studies in Mathematics, 58(3), $361-391$.

Stigler, J., \& Hiebert, J. (1999). The teaching gap: Best ideas from the world's teachers for improving education in the classroom. New York: Free Press.

Swan, M. (2007). The impact of task-based professional development on teachers' practices and beliefs: A design research study. Journal of Mathematics Teacher Education, 10(4-6), 217-237.

Teddlie, C., \& Tashakkori, A. (2003). Major issues and controversies in the use of mixed methods in the social and behavioral sciences. In A. Tashakkori \& $\mathrm{C}$. Teddlie (Eds.) Handbook of mixed methods in social and behavioral research (pp. 3-50). Thousand Oaks, CA: Sage.

Vappula, H., \& Clausen-May, T. (2006). Context in maths test questions: Does it make a difference? Research in Mathematics Education, 8(1), 99-115.

Watson, A. (2007). The nature of participation afforded by tasks, questions and prompts in mathematics classrooms. Research in Mathematics Education, 9(1), 111-126.

Watson, A. (2008). How secondary teachers structure the subject matter of mathematics. Proceedings of the British Society for Research Into Learning Mathematics, 28(3), 126-131.

Wilson, M., \& Cooney, T. (2002). Mathematics teacher change and developments: The role of beliefs. In G. Leder, E. Pehkonen, and G. Torner (Eds.), Beliefs: A hidden variable in mathematics education? (pp. 127-148). Dordrecht, Netherlands: Kluwer Academic Publishers. 